\title{
Internet gaming disorder in adolescents
}

\begin{abstract}
Objective: The aim of this study was to determine the status of internet gaming disorder in adolescents.

Material and Method: The study was planned in Child Health Clinic of Tepecik Training and Research Hospital, and the relevant scale was administered to children attending high school between April 2019 and June 2019. All survey questionnaire questions used in the study were handled as variables, gender and age variables were also taken into consideration.

Results: A total of 2246 students were reached, and 177 of them did not provide any information about what grade they were in. The remaining 2069 students were in the $9^{\text {th }}$ $(42.4 \%: n=953), 10^{\text {th }}(31.1 \%: n=703), 11^{\text {th }}(14.5 \%: n=326)$, and $12^{\text {th }}(3.9 \%: n=87)$ grade. A $56.1 \%$ of 2220 students who answered the question 'What is your gender?' were female students. As a response to the relevant question students indicated that they felt the need to spend an increasing amount of time playing games on internet most frequently to avoid negative emotions, and secondly to get satisfaction or enjoyment.
\end{abstract}

Conclusion: As a result, it is seen that internet gaming disorder, which is suggested to be investigated in DSM 5 and is a candidate for a new diagnosis, can be handled within the framework of a behavioral dependency. There is a need for further studies in terms of its incidence and effective factors related to this issue.

\author{
Volume 8 Issue 6 - 2019
}

\section{Dilek Orbatu, Demet Alaygut, Kayı Eliaçık \\ Department of Pediatrics, Tepecik Education and Research Hospital, Turkey}

Correspondence: Dilek Orbatu, Department of Pediatrics, Tepecik Education and Research Hospital,Turkey, Tel 90505755 65 79, Email drdilekorbatu@gmail.com

Received: December 15, 2019 | Published: December 24, 2019

\section{Introduction}

With the increase in the use of internet-related activities and the smart phones, the rapid assessment of technology is becoming increasingly popular worldwide. ${ }^{1,2}$ Following the acceptance of the term' internet dependency', the concept of internet gaming disorder (IGD) has begun to be emphasized. It was categorized as a behavioral addiction for the first time in the Diagnostic and Statistical Manual of Mental Disorders -5 (DSM-5) and included under the heading of nonsubstance related disorders. ${ }^{3}$ As a result of the adoption of the concept of behavioral addiction in DSM-5, the debates about whether some behaviors such as internet addiction, video games, sex and physical exercise can be included in this group have gained momentum. ${ }^{4}$ IGD is a potential mental health disorder. ${ }^{5}$ The cognitive pathologies underlying IGD are overly prone to the overwhelming importance given to awards from online games, to take on different identities, to participate in activities, and thus to be extremely inclined to play video games. ${ }^{5}$ IGD, mostly resembles gambling addiction in DSM5. IGD have 9 diagnostic criteria. These are concerns with internet games, feeling exhausted when being away from internet games, developing tolerance and increasing time spent on the internet, unsuccessful attempts to quit surfing on the internet, decreased enthusiasm in the fields of interests and hobbies, not being able to desist from playing games even though it is known that it will cause psychosocial problems. Misleading therapists and family members about the time spent during gaming, indulging in internet games to get away from negative moods, and missing friendship, work, education and career opportunities due to game addiction. ${ }^{6}$ Reaching consensus on the definition of IGD will speed up the diagnostic process, shape and guide treatment approaches. ${ }^{7}$

\section{Material and methods}

The study was planned in Tepecik Training and Research Hospital Pediatric Clinic and performed after approvals from the local ethics committee of the hospital and provincial directorate of national education were obtained. Metropolitan Province of Izmir is located on the west coast with highly developed socio-cultural status. There are 240,202 high school students in Izmir. Within the scope of this study, the students who were between the ages of 14-18 and continued their high school education in Izmir constituted the study population. As sampling method, stratified random sampling method was used based on this method, the sample size was calculated as 2401 with a margin of 0.2 errors, a power value of 0.80 , and a $95 \%$ confidence level. The survey questionnaire format was chosen as the data collection method. The study was conducted between April 2019 and June 2019 with the application of the nine-item Internet Gaming Disorder Scale (IGDS), which is one of the most popular DSM-5- based measurement tools to measure internet addiction among high school students at the international level. The scale consisting of 9 questions translated into Turkish by Arıcak OT et al. ${ }^{8}$

All questionnaire survey questions used in the study were regarded as variables and variables of gender and age were also taken into consideration. All descriptive statistics (relevant means, deviations, ranges, etc.) will be obtained. Relationship between variables was determined using correlation coefficients, for pair wise comparisons between variables $c h i$-square test, $\mathrm{t}$ - test, and $\mathrm{z}$ - test were used. ANOVA and Mann Whitney-U test were employed for the comparisons among more than two variables. The total score was obtained by averaging the answers given to each question, and the higher score indicated higher degree of dependence. 


\section{Results}

A total of 2246 students were reached, and 177 of them did not provide any information about what grade they were in. The remaining 2069 students were in the $9^{\text {th }}(42.4 \%$ : $n=953), 10^{\text {th }}(31.1 \%$ : $\mathrm{n}=703), 11^{\text {th }}(14.5 \%: \mathrm{n}=326)$, and $12^{\text {th }}(3.9 \%: \mathrm{n}=87)$ grade. A $56.1 \%$ of 2220 students who answered the question 'What is your gender?' were female students. A total of 152 students $(6.8 \%)$ answered the first question as 'very often'. Based on the responses to questionnaire survey questions, indicated percentages of students answered the following questions as 'very often': Does reducing gaming activity make you more irritable, anxious or sad? (3.7\%); 'Do you need to spend an increasing amount of time playing games to ensure satisfaction or enjoyment? (7.2\%), and finally 'Have you ever jeopardized an important relationship, education or career opportunity due to gaming activity? (3.7\%)'.Failure to try to control or quit gaming activity was stated by $4.7 \%$ of the respondents, while $3.7 \%$ of the students indicated they had lost interest in previous hobbies and entertainment as a result of indulging in gaming activities. Five percent of the participants said that they had continued to play games on internet even if it created difficulties in relationships with other people. Minority (3.7\%) of the students confessed that they had misled the family members, and therapists about the time spent gaming on internet. While $8.5 \%$ of the students indicated that they were gaming to refrain from a negative emotion, since any scale score was not encountered in the literature, the average score of each question was evaluated and the higher score indicated more serious game dependence. A statistically significant difference was found between grades in terms of total score. There was a statistically significant difference between 9 th and $11^{\text {th }}$ grades. In terms of gender, the total score of boys was higher than that of girls $(p=0.000)$. There was a statistically significant correlation between grades and total score $(\mathrm{p}=0.014)$ with a correlation coefficient of -0.054 . The tendency to video- game addiction decreased in higher grades.

\section{Discussion}

The first studies on internet dependency were conducted by Young in 1996. When Young conducted pioneering studies on internet dependency, it exacerbated a discussion among both clinicians and academicians. ${ }^{1,9}$ According to accessible international studies the prevalence of game dependency ranges between 0.6 , and $15 \% .^{10,11}$ When literature is screened related to online game dependency, It is seen that the few studies conducted on this issue are limited to aiming at identifying, and defining online game dependency, revealing the similarities with internet addiction, and determining the reasons why individuals prefer such games. ${ }^{12}$ It is generally possible to explain this finding by the fact that self-control increases with age. This finding also emphasizes the fact that individuals in younger age groups are at greater risk for online gaming addiction, ${ }^{12}$ when we look at the discriminatory features, it can be said that one of the most frequently mentioned concepts resembling internet gaming disorder (IGD) is internet addiction. ${ }^{13}$ One of the most confused points has been related to separate concepts of internet addiction and IGD. ${ }^{14}$ For example, although problematic internet use is seen in a wide range of groups with different characteristics, IGD is mostly seen in the young male population. In particular, adolescents are looking for prestige in their online gaming performances, while young adults can be motivated because they have the opportunity to express themselves. ${ }^{15}$ In parallel with this finding, it has been also reported that the individuals having IGD have fragile or instable self-esteem. ${ }^{16}$ On the other hand online games also meet one's need for success. Players can continue to play both to earn more and experience this sense of success. ${ }^{15}$ It is a global orientation that there is often a significant motivation on male gender in relation to success. Also in this study, the total score related to the scale applied in this study was found to be higher in male gender. Studies investigating gender differences in terms of IGD have revealed that this tendency is more frequently see in men than in women. Two explanations are recommended for this situation.

In the first statement, it was found that men's motivation of online gaming compared to women was based on maintaining more sense of success and establishing social communication. ${ }^{5}$ In the studies conducted, it has been discerned that the mean age of IGD patients indicate that adolescents and young adults are more prone to become victims of gaming addiction. This draws attention to the findings of the relationship between IGD and age of the netaholic. Indeed, it is reported that adolescents are the most risky group in developing IGD symptoms. ${ }^{17}$ Age is an important factor that faces us in the prevention and evaluation of IGD. (5) In our study, total score was found to be higher in the 9th grade namely approximately in the age group of 14-15 years, while dependency decreased in the 17 years of age. This condition may be related to the students' preparing for university entrance exams, so they are not interested much in playing online games.

In the literature, it is noteworthy that studies on the treatment of IGD are very limited and there is no treatment protocol developed specific to this disorder which is proven to be effective. It is correct to say that the treatments in the current studies are general intervention techniques mostly used for the prevention of internet addiction or that such treatments are adapted to IGD, ${ }^{18}$ to the best of our knowledge, there has not yet been an empirical study on treatment of IGD in this country. In our country, studies are needed related to both incidence, and effective factors on the development of IGD, and also intervention methods regarding internet gaming disorder. In particular, it is hoped that the development of programs preventing adolescents from becoming internet addicts, and the increase in the number of psycho education programs that will enable early diagnostic signs, and symptoms to be understood by families will prevent the spread of the IGD. We believe that our study will form the basic source for researches and implementations regarding this issue in our country and, therefore will provide the basis for prevention programs that can be developed and implemented in our country for a candidate psychiatric problem. Higher number of young population in Turkey, the intensive use of digital technology, inadequacy of control and preventive measures may further substantiate the development and augmentation of this problematic issue. However, there is a need for further research results related to digital gaming addiction among adolescents and young adults in Turkey. ${ }^{19}$

\section{Conclusion}

As a result, it is seen that internet gaming disorder, which is suggested to be investigated in DSM 5 and is a candidate for a new diagnosis, can be handled within the framework of a behavioral dependency. There is a need for conduction of studies about incidence rates, an effective factors and intervention methods regarding IGD in our country. It is necessary to develop prevention programs especially for adolescents and also psycho education programs that will enable early stage diagnostic signs, and symptoms to be understood by families. 


\section{Acknowledgments}

None.

\section{Conflicts of interest}

The author declares that there are no conflicts of interest.

\section{Funding}

None.

\section{References}

1. Young K. Understanding online gaming addiction and treatment issues for adolescents. The american Journal of Family Therapy. 2009;37(5):355-372.

2. Griffiths MD. The role of context in online gaming excess and addiction: Some case study evidence. International Journal of Mental Health Addiction. 2010;8:119-125.

3. Diagnostic and statistical manual of mental disorders (DSM-5). Washington, DC: American Psychiatric Publications. 2013.

4. Black DW, Coryell WC, Crowe RR et al. A direct, contrlled, blind family study of pathological gambling. J Clin Psychiatry. 2014;75(3):215-221.

5. MD Nazlıgül, S Baş, Z Akyüz, et al. Internet gaming disorder and treatment approaches: A systematic review. The Turkish Journal On Addictions. 2018; 5(1):28-35.

6. King DL, Delfabbro PH. Video-gaming disorder and the DSM-5: some further thoughts. Aust NZJ Psychiatry. 2013;47(9):875-876.

7. Phillips JG, Butt S, Blaszczynski A. Personality and self-reported use of mobile phones for games. Cyberpsychol Behav. 2006;9(6):753-758

8. Arıcak OT, Dinç M, Yay M, et al. Adapting the Short Form of the Internet Gaming Disorder Scale into Turkish: Validity and Reliability. The Turkish Journal of Addictions. 2018;5(4):1-8.

9. Van Rooij AJ, Schoenmakers TM, Vermulst AA, et al. Online videogame addiction: Identification of addicted adolescent gamers. Addiction. 2010;106(1):205-212.
10. Porter G,Starcevic V,Berle D, et al. Recognizing problem video game use. Aust N Z J Psychiatry. 2010;44(2):120-128.

11. Lemnens JS, Valkenburg PM, Peter J. Development and validation of a game addiction scale for adolescents. Media Psychol. 2009;12(1):77-95.

12. Madran Demirtaş HA, Çakılcı Ferligül E. The relationship between agresssion and online video game addiction: a study on massively multiplayer online video game players. Anadolu Psikiatri Derg. 2014;15(2):99-107.

13. Widyanto L, Griffiths MD, Brunsden V. A psychometric comparison of the Internet Addiction Test, the Internet-Related Problem Scale, and self-diagnosis. Cyberpsychol Behav Soc Netw. 2011;14(3):141-149.

14. Starcevic V, Portman ME. The status quo as a good outcome: How the DSM-5 diagnostic criteria for generalized anxiety disorder remained unchanged from the DSM-IV criteria. Aust N Z J Psychiatry. 2013;47(11):995-997.

15. Calado F, Alexandre J, Griffiths MD. Mom, dad it's only a game! Perceived gambling and gaming behaviors among adolescent and young adults: An exploratory study. International Journal of Mental Health and Addiction. 2014;12:772-794.

16. Beard CL, Wickham RE. Gaming - contingent self-worth, gaming motivation, and Internet Gaming Disorder. Computers in Human Behavior. 2014;11:149-161.

17. Müller KW, Jainikan M, Dreier M, et al. Regular gaming behavior and internet gaming disorder in European adolescents: Results from a cross-national prepresantative survey of prevelance, predictors, and psychopathological correlates. Eur Child Adolesc Psychiatry. 2015;24:565-574

18. Beranuy M, Carbonell X, Griffiths MD. A qualitative analysis of online gaming addicts in treatment. International Journal of mental health and Addiction. 2013;11:149-161 .

19. Yalçın Irmak A, Erdoğan S. Digital Game Addiction Among Adolescents and Younger Adults: A Current Overview. Türk Psikiatri Dergisi. 2016;27(2):128-137. 